Perceptual \& Motor Skills: Physical Development \& Measurement

2015, 121, 3, 923-934. (C) Perceptual \& Motor Skills 2015

\title{
PARKINSON'S DISEASE PATIENTS WITH DOMINANT HEMIBODY AFFECTED BY THE DISEASE RELY MORE ON VISION TO MAINTAIN UPRIGHT POSTURAL CONTROL ${ }^{1}$
}

\author{
JULIANA LAHR, MARCELO PINTO PEREIRA, PAULO HENRIQUE SILVA PELICIONI, \\ LUANA CAROLINA DE MORAIS, AND LILIAN TERESA BUCKEN GOBBI
}

UNESP-Universidade Estadual Paulista

\begin{abstract}
Summary.-This study assesses the association between disease onset side (dominant or non-dominant) and vision on postural control of Parkinson's disease patients. Patient volunteers composed two groups, according to the onset side affected: Dominant group $(n=9 ; M$ age $=66.1$ yr., $S D=7.2 ; 6$ women, 3 men) and Non-dominant group ( $n=9 ; M$ age $=67.4 \mathrm{yr}$., $S D=6.4 ; 6$ women, 3 men $)$. The groups' postural control was assessed by posturography during quiet upright stance in two conditions, Eyes open and Eyes closed. Two-way analyses of variance (ANOVAs; group $\times$ condition) with repeated measures for the second factor assessed the differences associated with affected hemibody and vision on postural control. Analyses indicated that patients with the dominant side affected also presented significantly greater variation in center of pressure than those with the non-dominant side affected, mainly in the Eyes closed condition. The results demonstrate a higher reliance on vision in the dominant side, possibly to compensate somatosensory system impairments. These results also highlight the importance of analyzing the hemibody affected by the disease when postural control is assessed in this population.
\end{abstract}

Parkinson's disease is characterized by asymmetric dopamine depletion in the basal ganglia (Kempster, Gibb, Stern, \& Lees, 1989; Djaldetti, $\mathrm{Ziv}$, \& Melamed, 2006). As a consequence, the severity of motor symptoms is different between the two sides of the body (hemibodies) (Louie, Koop, Frenklach, \& Bronte-Stewart, 2009; Haaxma, Helmich, Borm, Kappelle, Horstink, \& Bloem, 2010). This is also true when the axial impairments, such as postural control, are considered (Geurts, Boonstra, Voermans, Diender, Weerdesteyn, \& Bloem, 2011). The causes of asymmetric loss of dopamine in Parkinson's disease are still unknown, but the highest neuronal loss occurs contralaterally to the hemibody affected at onset (Kempster, et al., 1989). The cause of onset side is attributed to chance and is not related to any lateral dominance (Djaldetti, et al., 2006).

Previous studies investigating the side of disease onset have considered only the damage to the cerebral hemisphere (right vs left; Zucco, Zeni, \& Perrone, 2001; Amick, Grace, \& Chou, 2006; Katzen, Levin, \& Weiner, 2006) or the more or less affected side (Baumann, Held, Valko, Wienecke,

\footnotetext{
${ }^{1}$ Address correspondence to Juliana Lahr, Departamento de Educação Física, UNESP-Universidade Estadual Paulista, Rio Claro, Avenida 24-A, 1515 Bela Vista, Rio Claro-SP, 13506900, Brazil or e-mail (ju_lahr@hotmail.com).
} 
\& Waldvogel, 2014). However, they did not consider the relationship between lateral dominance and the affected hemibody. Although the causes are not known yet, the prevalence of the disease's onset is higher in the dominant side (van der Hoorn, Burger, Leenders, \& de Jong, 2012). This is particularly important, since some studies have suggested that the left cerebral hemisphere is more related to motor actions (Riederer \& Sian-Hülsmann, 2012; Caeyenberghs \& Leemans, 2014), while the right hemisphere is more related to cognitive processing (Verreyt, Nys, Santens, \& Vingerhoets, 2011; Riederer \& Sian-Hülsmann, 2012; Srovnalova, Marecek, Kubikova, \& Rektorova, 2012; Caeyenberghs \& Leemans, 2014). Therefore, it is suggested that in a right-handed sample those patients who present the right hemibody (dominant) as the onset side of the disease would show a higher neural degeneration in the hemisphere related to motor processing. In contrast, those who present with the non-dominant hemibody (left) as the disease onset should also have more intact basal ganglia in the left brain hemisphere. As a consequence, it is expected that in a right-handed sample patients with the dominant hemibody as the disease onset side would perform worse in motor tasks that require coordination and motor control using the affected side.

Another motor behavior that should be affected by the asymmetric dopamine depletion is the maintenance of upright posture. Geurts, et al. (2011) and Rocchi, Chiari, and Horak (2002) observed that postural control is asymmetric in moderate and advanced stages of the disease. However, these authors did not consider the effect of the side affected, dominant or non-dominant hemibody, on postural control.

It has been suggested that the postural control in the absence of visual information is controlled by the basal ganglia (Sarma, Cheng, Eden, Williams, Brown, \& Eskandar, 2012). However, when visual information is available the basal ganglia are bypassed for successful balance control (Takakusaki, Oohinata-Sugimoto, Saitoh, \& Habaguchi, 2004). Since the basal ganglia are impaired in Parkinson's disease, when less visual information is available the patient's postural control suffers (Azulay, Mesure, Amblard, \& Pouget, 2002; Vaugoyeau \& Azulay, 2010). Therefore, it is important to manipulate vision during postural control tasks in patients with Parkinson's disease. It is expected that a right-handed sample of patients with the dominant hemibody more affected by the disease, and therefore with more neural degeneration in the left hemisphere related to motor processing, would rely even more on vision to maintain upright postural control.

Investigating postural control in this population has a high ecological importance, since postural control is needed in perception of the environment (Jobst, Melnick, Byl, Dowling, \& Aminoff, 1997), maintenance of 
verticality (Barbieri, Gissot, Fouque, Casillas, Pozzo, \& Pérennou, 2008), balance, and body orientation (Benatru, Vaugoyeau, \& Azulay, 2008; Vaugoyeau \& Azulay, 2010). In addition, since dopamine supplementation does not effectively improve quiet upright stance control (Rocchi, et al., 2002), it is important to further investigate postural control behavior in Parkinson's disease, in order to establish possible non-pharmacological intervention strategies.

Hypothesis 1. Right-handed patients with Parkinson's disease with more motor impairment in the dominant hemibody will have poorer control of posture than patients with more motor impairment in the non-dominant hemibody.

Hypothesis 2. Right-handed patients with Parkinson's disease whose dominant hemibody is more affected by the disease will rely more on vision than those whose non-dominant hemibody is more affected.

\section{METHOD}

\section{Participants}

The participants were recruited from the local community, and 18 people accepted the invitation. The inclusion criteria included a medical diagnosis of idiopathic Parkinson's disease; unilateral impairment (Stage 1 or 1.5 according to the modified Hoehn and Yahr Rating Scale; Goetz, Poewe, Rascol, Sampaio, Stebbins, Counsell, et al., 2004); not being involved in any regular physical exercise program; age greater than 50 years; preserved cognitive functions [assessed by the Mini-Mental State Examination (MMSE); Brucki, Nitrini, Caramelli, Bertolucci, \& Okamoto, 2003]; and having the same hand and foot dominance (to ensure hemibody dominance). It was assumed that all participants maintained their hemibody dominance after disease onset. Patients with visual impairments that could not be corrected or with any other neurological or musculoskeletal conditions were excluded from the study sample. This study was approved by the local ethics committee, and the participants signed written consent to participate.

\section{Measures}

Parkinson's severity.-The unilateral/bilateral disease stage was defined according to the modified Hoehn and Yahr Rating Scale (Goetz, et al., 2004). To establish the Parkinson's disease onset side, the following criteria were used. (1) Self-reported side of onset of symptoms (Yust-Katz, Tesler, Treves, Melamed, \& Djaldetti, 2008) was recorded. (2) Difference between the right and left hemibody scores on six Unified Parkinson's Disease Rat- 
ing Scale (UPDRS) items was assessed (Items 20, 21, 22, 23, 25, and 26); a difference greater than 5 points was used to define the side of onset of the disease (Uitti, Baba, Whaley, Wszolek, \& Putzke, 2005). Considering the disease onset and the lateral dominance, the participants were classified into two groups: dominant side affected (Dominant) or non-dominant side affected (Non-dominant). Manual dominance was defined as the hand usually used to write (Yust-Katz, et al., 2008) and the foot dominance as the limb used to kick a ball (Peters, 1988).

Cognitive status.-The participants' cognitive status was assessed using the MMSE, which comprises seven categories: time orientation, place orientation, registration of the words, attention and calculation, recall of the words mentioned, language, and visual construction capacity. Brucki, et al.'s (2003) suggestions to determine the MMSE cutoff score according to educational level in Brazil were used. Higher scores represent more preserved cognitive function. No participants showed signs of cognitive impairment or dementia.

Postural control.-Posturography was done during a quiet upright stance in two conditions, Eyes open and Eyes closed. To standardize the patients' position during each trial, they were asked to stand in a quiet upright position, looking straight ahead, with their arms resting at the sides of the body. Feet positions were also kept constant across trials (Termoz, Halliday, Winter, Frank, Patla, \& Prince, 2008). During the Eyes closed condition, the participants were blindfolded with an ordinary eye mask. Two attempts lasting $30 \mathrm{sec}$. for each condition were performed in the following order: Eyes open and Eyes closed.

A force plate (Model AccuGait, Advanced Mechanical Technologies, $50 \times 50 \mathrm{~cm}$ ) was used, calibrated with $100 \mathrm{~Hz}$ data acquisition frequency. The Balance Clinic (Advanced Mechanical Technologies, MA, USA) software was used to assess the following center of pressure variables: total velocity (CoP total velocity) and area (CoP area; Błaszczyk \& Orawiec, 2011). The CoP area was determined using the 95\% confidence elipse (Moghadam, Ashayer, Salavati, Sarafzadeh, Taghipoor, \& Saeedi, et al., 2011).

\section{Procedure}

All assessments were done in the "on-medication" state, $1 \mathrm{hr}$. after dose of medication. The daily levodopa equivalent dose was calculated according to established methods (Tomlinson, Stowe, Patel, Rick, Gray, \& Clarke, 2010). Patients' symptoms and disease severity were assessed using the UPDRS (Fahn \& Elton, 1987). For the classification, Subscale I (psychological functions), Subscale II (activity daily living functions), Subscale III (motor functions), and Subscale IV (dyskinesia) were used.

The two groups were composed of nine participants each (pairs matched by sex: 6 women and 3 men per group) with similar age, body 
height, body mass, psychological functions (UPDRS I), activity daily living functions (UPDRS II), motor impairment (UPDRS III), total disease impairment (UPDRS Total), disease duration, and cognitive status (MMSE). No participant showed severe dyskinesia. The Non-dominant group had a higher mean daily levodopa equivalent dose than the Dominant group, but the dopamine supplementation was not effective in improving control of the quiet upright stance (Rocchi, et al., 2002) and so did not interfere with results (Table 1 ).

Analysis

All data were analyzed using specific MATLAB (Version 7.0, MathWorks ${ }^{\circledR}$ Inc.) algorithms. All results were averaged across trials and across participants of each group. Therefore, the mean values of each group +1 standard deviation are shown for each variable. All statistical procedures were conducted in Statistica 7.0 for Windows. A two-way analysis of variance (ANOVA; group $\times$ condition) with repeated measures for the second factor was used to assess the association of affected hemibody and vision on the performance of postural control. A Tukey post hoc test was used to assess univariate differences. The alpha level was set $a$ priori at $p \leq .05$.

\section{RESULTS}

The values of all variables for both groups (Dominant and Non-dominant) and conditions (Eyes open and Eyes closed) are shown in Table 2. An interaction between group and condition was observed for CoP total velocity $\left(F_{1,16}=9.52, p=.01, \eta_{p}^{2}=0.37\right.$, observed power $\left.=0.99\right)$. The post hoc test showed a higher total velocity in the Eyes closed versus Eyes open condition in both groups (Dominant group: $p<.001$ and Non-dominant group: $p=.01$ ). This result means that without vision information Parkinson's disease patients show higher CoP velocity, affecting postural control. Furthermore, the post hoc test also showed a higher total velocity in the Dominant group in comparison to the Non-dominant group in the Eyes closed condition $(p=.03)$, so patients whose dominant hemibody was more affected by disease had worse postural control with eyes closed than those patients for whom the non-dominant hemibody was more affected by the disease. The interaction can be observed in Fig. 1.

For CoP area, a main effect of condition was also found $\left(F_{1,16}=4.50\right.$, $p=.05, \eta_{\mathrm{p}}^{2}=0.22$, observed power $\left.=0.98\right)$. For both groups, the Eyes closed condition (Dominant group: $M=1.87 \mathrm{~cm}^{2}, S D=2.52$; Non-dominant group: $\left.M=1.13 \mathrm{~cm}^{2}, S D=1.07\right)$ was more challenging than the Eyes open condition (Dominant group: $M=1.15 \mathrm{~cm}^{2}, S D=1.55$; Non-dominant group: $M=$ $1.03 \mathrm{~cm}^{2}, S D=0.82$ ). There was no main effect of group nor interaction between factors for this variable $\left(F_{1,16}=0.34, p=.57, \eta_{\mathrm{p}}^{2}=0.02\right.$, observed power $=0.22 ; F_{1,16}=2.63, p=.12, \eta_{\mathrm{p}}^{2}=0.14$, observed power $=0.76$ ). 
TABLE 1

Independent $T$ Tests Comparing Demographics and Clinical Characteristics For EACH Group

\begin{tabular}{|c|c|c|c|c|c|c|}
\hline Variable & & $\begin{array}{c}\text { Dominant } \\
\text { Group } \\
(n=9)\end{array}$ & $\begin{array}{l}\text { Non-domi- } \\
\text { nant Group } \\
(n=9)\end{array}$ & $t_{1,16}$ & $p$ & Cohen's $d$ \\
\hline Dominant side & & Right & Right & & & \\
\hline Side affected & & Right & Left & & & \\
\hline \multirow[t]{2}{*}{ Age, yr. } & $M$ & 66.11 & 67.44 & \multirow{2}{*}{-0.41} & \multirow{2}{*}{.69} & \multirow{2}{*}{-0.19} \\
\hline & $S D$ & 7.29 & 6.41 & & & \\
\hline \multirow[t]{2}{*}{ Body height, cm } & $M$ & 158.3 & 160.59 & \multirow{2}{*}{-0.54} & \multirow{2}{*}{.60} & \multirow{2}{*}{-0.25} \\
\hline & $S D$ & 9.5 & 8.4 & & & \\
\hline \multirow[t]{2}{*}{ Body mass, kg } & $M$ & 68.25 & 65.7 & \multirow{2}{*}{0.51} & \multirow{2}{*}{.62} & \multirow{2}{*}{0.23} \\
\hline & $S D$ & 8.42 & 12.54 & & & \\
\hline \multirow[t]{2}{*}{ H\&Y, score } & $M$ & 1.28 & 1.39 & \multirow{2}{*}{3.11} & \multirow{2}{*}{.10} & \multirow{2}{*}{-0.45} \\
\hline & $S D$ & 0.26 & 0.22 & & & \\
\hline \multirow[t]{2}{*}{ UPDRS I, score } & $M$ & 2.33 & 3.44 & \multirow{2}{*}{-1.39} & \multirow{2}{*}{.19} & \multirow{2}{*}{-0.65} \\
\hline & $S D$ & 1.73 & 1.67 & & & \\
\hline \multirow[t]{2}{*}{ UPDRS II, score } & $M$ & 9.89 & 12.67 & \multirow{2}{*}{-1.38} & \multirow{2}{*}{.19} & \multirow{2}{*}{-0.65} \\
\hline & $S D$ & 3.95 & 4.55 & & & \\
\hline \multirow[t]{2}{*}{ UPDRS III, score } & $M$ & 19.11 & 21.89 & \multirow{2}{*}{-0.69} & \multirow{2}{*}{.50} & \multirow{2}{*}{-0.32} \\
\hline & $S D$ & 7.44 & 9.49 & & & \\
\hline \multirow[t]{2}{*}{ UPDRS IV, score } & $M$ & 0.33 & 0.44 & \multirow{2}{*}{-0.33} & \multirow{2}{*}{.75} & -015 \\
\hline & $S D$ & 0.71 & 0.73 & & & 0.10 \\
\hline UPDRS Total, score & $M$ & 31.33 & 38 & & 24 & \\
\hline & $S D$ & 11.61 & 11.51 & -1.22 & .24 & -0.57 \\
\hline Duration of disease, yr. & $M$ & 4.00 & 6.56 & -17 . & 11 & -080 \\
\hline & $S D$ & 2.78 & 3.54 & 1.00 & .11 & 0.00 \\
\hline MMSE, score & $M$ & 27.77 & 27.77 & 0.74 & .40 & 0 \\
\hline & $S D$ & 1.71 & 3.19 & & & \\
\hline Education, yr. & $M$ & 7.78 & 7.22 & 023 & 82 & 011 \\
\hline & $S D$ & 5.26 & 4.89 & 0.23 & .82 & 0.11 \\
\hline LED, mg/day & $M$ & 547.88 & 926.67 & -3.00 & 01 & -141 \\
\hline & $S D$ & 304.4 & 225.36 & & & \\
\hline
\end{tabular}

Note.-Student's $t$ tests were employed for between-group comparisons at the baseline. H\&Y: modified Hoehn and Yahr Rating Scale; UPDRS I: Unified Parkinson's Disease Rating Scale, Subscale I; UPDRS II: Unified Parkinson's Disease Rating Scale, Subscale II; UPDRS III: Unified Parkinson's Disease Rating Scale, Subscale III; UPDRS Total: Unified Parkinson's Disease Rating Scale, total scale; MMSE: Mini-Mental State Examination; LED: levodopa equivalent dose. 
TABLE 2

Two-way Repeated-measures Analyses of Variance: Impact of the Results of Side Affected and Visual Information on the Postural Control

\begin{tabular}{|c|c|c|c|c|c|c|c|c|c|c|}
\hline & \multicolumn{5}{|c|}{ CoP Total Velocity } & \multicolumn{5}{|c|}{ CoP Area } \\
\hline & $d f$ & MSE & $F$ & $p$ & $\eta_{\mathrm{p}}^{2}$ & $d f$ & MSE & $F$ & $p$ & $\eta_{p}^{2}$ \\
\hline Group (G) & 1 & 0.14 & 10.75 & .01 & 0.40 & 1 & 0.07 & 0.34 & .57 & 0.02 \\
\hline $\begin{array}{l}\text { Conditions } \\
\text { (C) }\end{array}$ & 1 & 0.11 & 64.65 & $<.001$ & 0.80 & 1 & 0.06 & 4.51 & .05 & 0.22 \\
\hline $\mathrm{G} \times \mathrm{C}$ & 1 & 0.02 & 9.52 & .01 & 0.37 & 1 & 0.03 & 2.63 & .13 & 0.14 \\
\hline
\end{tabular}

Note.-CoP total velocity: total velocity of center of pressure; COP area: area of center of pressure.

\section{DISCUSSION}

Supporting Hypothesis 1, the results indicated that patients with their dominant side affected had significantly poorer postural control than patients with their nondominant side affected by the disease. Also, a significantly higher reliance on vision for postural control in the Dominant group supported Hypothesis 2.

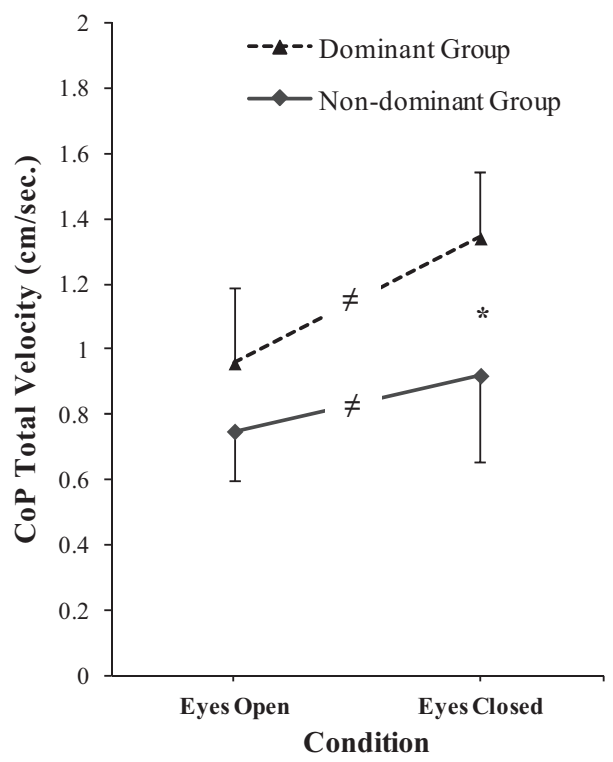

FIG. 1. Interaction between group and condition for CoP total velocity. CoP total velocity: total velocity of center of pressure; $\neq$ : difference between conditions (Eyes Open and Eyes Closed) within the group; *: difference between group (Dominant Group and Non-dominant Group) within the condition. 
Patients with Parkinson's disease have poorer postural control than healthy people of the same age and lateral dominance (Vaugoyeau \& Azulay, 2010), particularly when vision is not available (Azulay, et al., 2002). They also show somatosensory system impairments (Jobst, et al., 1997; Rocchi, et al., 2002). Geurts, et al. (2011) showed that these patients could not control their posture enough to distribute weight equally on each foot. Similarly, somatosensory feedback impairments apparently cause errors in detecting the position of center of pressure (Rocchi, et al., 2002). Moreover, patients with Parkinson's disease distribute weight unevenly across their body when their eyes are closed (Kitamura, Nakagawa, Iinuma, Kobayashi, Okauchi, Oonaka, et al., 1993). Patients use visual information as an adaptive strategy to partially compensate for an impaired somatosensory system (Abbruzzese \& Berardelli, 2003; Vaugoyeau \& Azulay, 2010).

The basal ganglia are an important center in somatosensory processing (Conte, Khan, Defazio, Rothwell, \& Berardelli, 2013; Müller, Albin, Kotagal, Koeppe, Scott, Frey, et al., 2013), and degeneration of basal ganglia has been suggested as the major cause of postural control impairment in Parkinson's disease (Takakusaki, Habaguchi, Ohtinata-Sugimoto, Saitoh, \& Sakamoto, 2003). Based on the current results (Table 2), because of the likely impairment in the basal ganglia associated with Parkinson's disease, postural control was worse when only somatosensory information was available in the Eyes closed condition. These results are in agreement with previous findings showing that patients with Parkinson's disease rely on vision to maintain upright postural control. However, in the current study this was only true for patients whose dominant side was affected. In addition, the Dominant group had poorer performance than the Non-dominant group only in the Eyes closed condition (Table 2 and Fig. 1).

However, the sample was composed of only right-handed participants, which means that the left brain hemisphere was more affected in the group with their dominant side affected. Previous studies have suggested that the left brain hemisphere is more involved in motor programming (Riederer \& Sian-Hülsmann, 2012; Caeyenberghs \& Leemans, 2014), while the right one is more involved in cognitive processes (Verreyt, et al., 2011; Riederer \& Sian-Hülsmann, 2012; Srovnalova, et al., 2012; Caeyenberghs \& Leemans, 2014). Because in the Dominant side affected group the left brain hemisphere was more affected by the disease, it should be expected that their performance would be lower in a motor task like upright posture maintenance. When the lower ability to process motor information was considered in conjunction with the baseline sensory impairment in patients with Parkinson's disease, it was not unexpected that the Dominant side affected group would perform worse when vision was absent. Vieira, Coelho, and Teixeira (2014) observed that healthy young adults 
controlled the postural threat using their right leg when executing a lowmagnitude posture task. This last finding (Vieira, et al., 2014) supports the hypothesis that participants use the right hemibody (controlled by the leftbrain hemisphere) to maintain/reestablish postural control. On the other hand, Pérennou, Mazibrada, Chauvineau, Greenwood, Rothwell, Gresty, et al. (2004) showed in stroke patients a right-hemisphere dominance to body orientation control in respect to gravity. As it can be seen, this is still an open debate, and in the authors' understanding this is the first study to consider the preference-affected hemibody relation in postural control in people with Parkinson's disease. Therefore, the hypothesis will need to be tested in future studies by checking whether the parallel and opposite relationship can be observed in a left-handed sample.

Štochl, Croudace, Brožová, Klempír, Roth, and Růžička (2012) showed there was a shift in the hemibody dominance if the preferred side was initially affected by the disease. Specifically, during the course of the disease patients begin to perform motor tasks with the unaffected hemibody. Therefore, to ensure that patients have not changed their hemibody dominance, only patients with a single hemibody affected by the disease were assessed; i.e., all participants were in Hoehn and Yahr stages 1-1.5. Thus, further studies should investigate these changes in dominance during the course of the disease.

The results of this study have important implications for clinical assessment and intervention routines, since patients who develop the first Parkinson's disease symptoms in the dominant or non-dominant hemibody behave differently in motor tasks. This relationship should be considered and applied in rehabilitative and preventive programs.

The small sample size and the use of a single force plate are limitations of the current study. To investigate the asymmetrical postural control deficits in Parkinson's disease, the use of two force plates to acquire the center of pressure is advised. Also, although the present study used only a small sample size, large effect sizes were found, indicating these are substantial effects and that the number of patients assessed was sufficient.

\section{REFERENCES}

Abbruzzese, G., \& Berardelli, A. (2003) Sensorimotor integration in movement disorders. Movement Disorders, 18(3), 231-240.

Amick, M. M., Grace, J., \& Chou, K. L. (2006) Body side of motor symptom onset in Parkinson's disease is associated with memory performance. Journal of the International Neuropsychological Society, 12(5), 736-740.

Azulay, J. P., Mesure, S., Amblard, B., \& Pouget, J. (2002) Increased visual dependence in Parkinson's disease. Perceptual \& Motor Skills, 95(3, Pt. 2), 1106-1114.

Barbieri, G., Gissot, A. S., Fouque, F., Casillas, J. M., Pozzo, T., \& Pérennou, D. (2008) Does proprioception contribute to the sense of verticality? Experimental Brain Research, 185(4), 545-552. 
Baumann, C. R., Held, U., Valko, P. O., Wienecke, M., \& Waldvogel, D. (2014) Body side and predominant motor features at the onset of Parkinson's disease are linked to motor and nonmotor progression. Movement Disorders, 29(2), 207-213.

Benatru, I., Vaugoyeau, M., \& Azulay, J. P. (2008) Postural disorders in Parkinson's disease. Neurophysiologie Clinique/Clinical Neurophysiology, 38(6), 459-465.

BŁaszCZYK, J. W., \& OraWiec, R. (2011) Assessment of postural control in patients with Parkinson's disease: sway ratio analysis. Human Movement Science, 30(2), 396-404.

Brucki, S. M., Nitrini, R., Caramelli, P., Bertolucci, P. H., \& OKamoto, I. H. (2003) Suggestions for utilization of the mini-mental state examination in Brazil. Arquivos de Neuro-Psiquiatria, 61(3B), 777-781.

Caeyenberghs, K., \& Leemans, A. (2014) Hemispheric lateralization of topological organization in structural brain networks. Human Brain Mapping, 35(9), 4944-4957.

Conte, A., Khan, N., Defazio, G., Rothwell, J. C., \& Berardelli, A. (2013) Pathophysiology of somatosensory abnormalities in Parkinson disease. Nature Reviews Neurology, 9(12), 687-697.

DjaldetTI, R., Ziv, I., \& Melamed, E. (2006) The mystery of motor asymmetry in Parkinson's disease. The Lancet Neurology, 5(9), 796-802.

Fahn, S., Elton, R. L., \& Members of the UPDRS Development Committee. (1987) Unified Parkinson's Disease Rating Scale. In S. Fahn, C. D. Marsden, M. Goldstein, \& D. B. Calne (Eds.), Recent developments in Parkinson's disease. Vol. 2. Florham Park, NJ: Macmillan Healthcare Information. Pp. 153-163.

Geurts, A. C. H., Boonstra, T. A., Voermans, N. C., Diender, M. G., Weerdesteyn, V., \& Bloem, B. R. (2011) Assessment of postural asymmetry in mild to moderate Parkinson's disease. Gait \& Posture, 33(1), 143-145.

Goetz, C. G., Poewe, W., Rascol, O., Sampaio, C., Stebbins, G. T., Counsell, C., Giladi, N., Holloway, R. G., Moore, C. G., Wenning, G. K., Yahr, M. D., \& Seidl, L. (2004) Movement Disorder Society Task Force report on the Hoehn and Yahr staging scale: status and recommendations. Movement Disorders, 19(9), 1020-1028.

Haaxma, C. A., Helmich, R. C. G., Borm, G. F., Kappelle, A. C., Horstink, M. W. I. M., \& Bloem, B. R. (2010) Side of symptom onset affects motor dysfunction in Parkinson's disease. Neuroscience, 170(4), 1282-1285.

Jobst, E. E., Melnick, M. E., Byl, N. N., Dowling, G. A., \& Aminoff, M. J. (1997) Sensory perception in Parkinson disease. Archives of Neurology, 54(4), 450-454.

Louie, S., Koop, M. M., Frenklach, A., \& Bronte-Stewart, H. (2009) Quantitative lateralized measures of bradykinesia at different stages of Parkinson's disease: the role of the less affected side. Movement Disorders, 24(13), 1991-1997.

Katzen, H. L., Levin, B. E., \& Weiner, W. (2006) Side and type of motor symptom influence cognition in Parkinson's disease. Movement Disorders, 21(11), 1947-1953.

Kempster, P. A., Gibb, W. R. G., Stern, G. M., \& Lees, A. J. (1989) Asymmetry of substantia nigra neuronal loss in Parkinson's disease and its relevance to the mechanism of levodopa related motor fluctuations. Journal of Neurology, Neurosurgery, E Psychiatry, 52(1), 72-76.

Kitamura, J., Nakagana, H., Iinuma, K., Kobayashi, M., Okauchi, A., Oonaka, K., \& Kondo, T. (1993) Visual influence on center of contact pressure in advanced Parkinson's disease. Archives of Physical Medicine and Rehabilitation, 74(10), 1107-1112.

Moghadam, M., Ashayer, H., Salavati, M., Sarafzadeh, J., Taghipoor, K. D., Saeedi, A., \& SALEHI, R. (2011) Reliability of center of pressure measures of postural stability in healthy older adults: effects of postural task difficulty and cognitive load. Gait $\mathcal{E}$ Posture, 33(4), 651-655. 
Müller, M. L., Albin, R. L., Kotagal, V., Koeppe, R. A., Scott, P. J., Frey, K. A., \& Bohnen, N. I. (2013) Thalamic cholinergic innervation and postural sensory integration function in Parkinson's disease. Brain, 136(Pt. 11), 3282-3289.

Pérennou, D. A., Mazibrada, G., Chauvineau, V., Greenwood, R., Rothwell, J., Gresty, M. A., \& BronsteIn, A. M. (2008) Lateropulsion, pushing and verticality perception in hemisphere stroke: a causal relationship? Brain, 131(Pt. 9), 2401-2413.

Peters, M. (1988) Footedness asymmetries in foot preference and skill and neuropsychological assessment of foot movement. Psychological Bulletin, 103(2), 179-192.

Riederer, P., \& Sian-Hülsmann, J. (2012) The significance of neuronal lateralisation in Parkinson's disease. Journal of Neural Transmission, 119(8), 953-962.

Rocchi, L., Chiari, L., \& HoraK, F. B. (2002) Effects of deep brain stimulation and levodopa on postural sway in Parkinson's disease. Journal of Neurology, Neurosurgery, E Psychiatry, 73(3), 267-274.

Sarma, S. V., Cheng, M. L., Eden, U., Williams, Z., Brown, E. N., \& Eskandar, E. (2012) The effects of cues on neurons in the basal ganglia in Parkinson's disease. Frontiers in Integrative Neuroscience, 6(40), 1-12.

Srovnalova, H., MareceK, R., Kubikova, R., \& Rektorova, I. (2012) The role of the right dorsolateral prefrontal cortex in the Tower of London task performance: repetitive transcranial magnetic stimulation study in patients with Parkinson's disease. Experimental Brain Research, 223(2), 251-257.

Štochl, J., CRoudace, T. J., BrožOvÁ, H., KlemPír, J., Roth, J., \& RŮŽIČKA, E. (2012) Changes of hand preference in Parkinson's disease. Journal of Neural Transmission, 119(6), 693-696.

TaKaKusaki, K., Habaguchi, T., Ohtinata-Sugimoto, J., Saitoh, K., \& SAKamoto, T. (2003) Basal ganglia efferents to the brainstem centers controlling postural muscle tone and locomotion: a new concept for understanding motor disorders in basal ganglia dysfunction. Neuroscience, 119(1), 293-308.

TAKAKUSAKI, K., OOHINATA-Sugimoto, J., SAitoH, K., \& Habaguchi, T. (2004) Role of basal ganglia-brainstem systems in the control of postural muscle tone and locomotion. Progress in Brain Research, 143, 231-237.

Termoz, N., Halliday, S. E., Winter, D. A., Frank, J. S., Patla, A. E., \& Prince, F. (2008) The control of upright stance in young, elderly and persons with Parkinson's disease. Gait \& Posture, 27(3), 463-470.

Tomlinson, C. L., Stowe, R., Patel, S., Rick, C., Gray, R., \& Clarke, C. E. (2010) Systematic review of levodopa dose equivalency reporting in Parkinson's disease. Movement Disorders, 25, 2649-2685.

Uitti, R. J., Baba, Y., Whaley, N. R., Wszolek, Z. K., \& PutZKe, J. D. (2005) Parkinson disease: handedness predicts asymmetry. Neurology, 64(11), 1925-1930.

van der Hoorn, A., Burger, H., Leenders, K. L., \& DE Jong, B. M. (2012) Handedness correlates with the dominant Parkinson side: a systematic review and meta-analysis. Movement Disorders, 27(2), 206-210.

Vaugoyeau, M., \& Azulay, J. (2010) Role of sensory information in the control of postural orientation in Parkinson's disease. Journal of the Neurological Sciences, 289(12), 66-68.

Verreyt, N., Nys, G. M. S., Santens, P., \& Vingerhoets, G. (2011) Cognitive differences between patients with left-sided and right-sided Parkinson's disease: a review. Neuropsychology Review, 21(4), 405-424. 
Vieira, O., Jr., Coelho, D. B., \& Teixeira, L. A. (2014) Asymmetric balance control between legs for quiet but not for perturbed stance. Experimental Brain Research, 232(10), 3269-3276.

Yust-Katz, S., Tesler, D., Treves, T. A., Melamed, E., \& Djaldetti, R. (2008) Handedness as a predictor of side of onset of Parkinson's disease. Parkinsonism E Related Disorders, 14(8), 633-635.

Zucco, G., Zeni, M. T., \& Perrone, A. (2001) Olfactory sensitivity in early-stage Parkinson patients affected by more marked unilateral disorder. Perceptual \& Motor Skills, 92(3, Pt. 1), 894-898.

Accepted October 20, 2015. 